\title{
Espiritualidade/religiosidade dos familiares de usuários de crack como processo na recuperação
}

\author{
Spirituality/religiosity of the relatives of crack users as recovery process \\ Espiritualidad / religiosidad de los familiares de usuarios de crack como proceso en la \\ recuperación
}

Elinéia dos Santos Fontes ${ }^{1}$; Maria da Conceição Quirino dos Santos ${ }^{1-2}$; Sérgio Donha Yarid²; Renara Meira Gomes ${ }^{1 *}$; Maria Lúcia Quirino dos Santos ${ }^{1}$; Ianderlei Andrade Souza ${ }^{2}$; Kay Amparo Santos ${ }^{1-}$ 2; Norma Lopes de Magalhães Velasco Bastos ${ }^{2}$; Sheylla Nayara Sales Vieira ${ }^{1-2}$; Geovana de Jesus Santana ${ }^{1}$

\section{RESUMO}

Objetivo: Compreender a vivência e estratégias de enfrentamento de familiares de usuários de crack, através da análise de intervenções religiosas emergentes para recuperação. Métodos: Trata-se de uma pesquisa de abordagem qualitativa do tipo revisão de literatura. Sendo usado como fontes de dados artigos publicados nas bases de dados do SciELO (Scientific Eletronic Library Online), REDALYC (Red de Revistas Científicas de América Latina y el Caribe, España y Portugal), Periódicos CAPES (Portal de Periódicos, da Coordenação de Aperfeiçoamento de Pessoal de Nível Superior), Periódicos da Kroton, BVS (Biblioteca Virtual em Saúde) e Google acadêmico, compreendendo o período de 2012 a 2018. Resultados: Percebe-se uma significativa evolução da dependência química, especificamente o crack, pois se tornou um grave problema de saúde pública associado a fatores biopsicossociais. A religiosidade/espiritualidade são fatores positivos aliados como suporte a família. Conclusão: Diante do sofrimento vivido por familiares e dependentes químicos em consequência do uso do crack, os indivíduos voltam-se à religiosidade como apoio no enfrentamento da doença, favorecendo assim seu bemestar. Desta forma, a religiosidade/espiritualidade são fatores positivos aliados ao processo de recuperação, onde é notável as mudanças nos hábitos de vida e melhor interação familiar e social.

Palavras-chaves: Relações familiares, Dependência química, Espiritualidade, Religiosidade.

\begin{abstract}
Objective: To Understand the living and coping strategies of family of users of crack, through the analysis of emerging religious interventions for recovery. Method: This is a qualitative survey of the literature review type, being used as data sources published articles in databases of the SciELO (Scientific Electronic Library Online), REDALYC (network of scientific journals of Latin America and the Caribbean, España y Portugal), CAPES Journals (Periodical Portal, the Coordenação de Aperfeiçoamento de Pessoal de Nível Superior), journals of Kroton, the VHL (Virtual Health Library) and Google Scholar, the period from 2012 to 2018. Results: There is a significant evolution of chemical dependence, specifically crack, as it has become a serious public health problem associated with biopsychosocial factors. Religiousness / spirituality are positive allies as support for the family. Conclusion: in the face of the suffering experienced by family members and addicts in consequence of the use of crack, individuals turn to religiosity as support in the fight against the disease, favoring so your well-being. In this way, the religiousness/spirituality are positive factors to recovery process, where remarkable changes in life habits and better family and social interaction.
\end{abstract}

Keywords: Family relationships, Chemical dependency, Spirituality, Religiosity.

\footnotetext{
${ }^{1}$ Faculdade de Tecnologia e Ciências - Jequié, Bahia, Brasil. * E-mail: nara rhema@hotmail.com

2 Universidade Estadual do Sudoeste da Bahia/UESB - Jequié, Bahia, Brasil.
} 


\section{RESUMEN}

Objetivo: Comprender la vivencia y estrategias de enfrentamiento de familiares de usuarios de crack, a través del análisis de intervenciones religiosas emergentes para recuperación. Métodos: Se trata de uma investigación de abordaje cualitativo del tipo revisión de literatura. Se utiliza como elementos de fuentes de datos publicados en las bases de datos SciELO (Scientific Electronic Library Online), Redalyc (Red de Revistas Científicas de América Latina y el Caribe, España y Portugal), capas diarios (Diario Portal, Coordinación de Mejora de Personal de Nivel Superior), Periódicos de Kroton, BVS (Biblioteca Virtual en Salud) y Google académico, comprendiendo el período de 2012 a 2018. Resultados: Se percibe una significativa evolución de la dependencia química, específicamente el crack, pues se ha convertido en un grave problema de salud pública asociado a factores biopsicosociales. La religiosidad / espiritualidad son factores positivos aliados como soporte a la familia. Conclusión: Ante el sufrimiento vivido por familiares y dependientes químicos como consecuencia del uso del crack, los individuos se vuelven a la religiosidad como apoyo en el enfrentamiento de la enfermedad, favoreciendo así su bienestar. De esta forma, la religiosidad / espiritualidad son factores positivos aliados al proceso de recuperación, donde es notable los cambios en los hábitos de vida y mejor interacción familiar y social.

Palabras claves: Relaciones familiares, Dependencia química, Espiritualidad, Religiosidad.

\section{INTRODUÇÃO}

A dependência química vem se propagando ao longo dos anos de forma frenética, evidenciando um alto nível de transtornos psiquiátricos e doenças relacionados ao uso das drogas, principalmente entre adolescentes e jovens. Ela é considerada como uma doença crônica que pode ser tratada e controlada, conduzindo o indivíduo a mudanças no comportamento e adaptação ao processo de doença. Nesta percepção, a dependência química é caracterizada como problema de saúde pública, de cunho progressivo, evolução própria, incurável, mas tratável (SILVA et al, 2015; MACIEL et al, 2013).

O intenso consumo de drogas psicotrópicas, notadamente o crack, é um problema de proporções epidêmicas que abrange todos os elementos da sociedade, ocasionando grandes impactos em todos os âmbitos da vida do dependente químico e, consequentemente, na organização familiar (PAULA et al, 2014; JORGE et al, 2013).

Um dos primeiros registros de consumo do crack no país foi data da década de 90 , daí por diante vem crescendo nas capitais e no interior. No ano de 2012, o Brasil foi mencionado como o maior comércio mundial de consumo de crack. Estima-se que 1,2 milhões de brasileiros sejam dependentes dessa droga, correspondendo aproximadamente a um percentual de 0,6\%, referente ao total de habitantes do país (CAPISTRANO et al, 2013).

O crack é a mistura da pasta não refinada de cocaína com bicarbonato de sódio e água. Possui rápido efeito excitativo de curta duração quando fumado. É apresentado em forma de pedras e tem maior potencial destrutivo do que a cocaína refinada. Sabe-se que as consequências relativas ao consumo do crack são atenuantes em relação às da cocaína, com destaque dos sintomas psiquiátricos, que se apresentam mais frequentes. A overdose continua como a complicação mais conhecida, entre usuários e população em geral, mesmo não sendo tão frequente (MARQUES et al, 2012). Contudo, o consumo ininterrupto desta substância levará o indivíduo a dependência e por se tratar de um transtorno crônico, a pessoa poderá apresentar episódios de recaídas. Portanto, todo esse processo conduzirá o dependente a diversos prejuízos, sejam eles de ordem física, psíquica, social e familiar (PAULA et al, 2014; JORGE et al, 2013).

Todos do convívio social sofrem com os impactos trazidos pelo uso abusivo do crack, especialmente os dependentes e seus familiares. A família é a primeira sociedade que o indivíduo faz parte e onde iniciam os primeiros passos de formação da personalidade e do caráter. É nela que o dependente químico precisará encontrar o apoio primordial para sua recuperação. Em geral, a família é a primeira que descobre o problema do uso de drogas dentro da convivência familiar. Esta deverá prezar pelo cuidado, proteção e buscas para o tratamento, seja ele de cunho medicinal e/ou espiritual (XAVIER et al, 2014; AZEVEDO E SILVA, 2013; PAZ E COLOSSI, 2013).

Os integrantes da família enfrentam situações de angústia, medo, culpa, tristeza, impotência no autocontrole e outros sentimentos durante o processo terapêutico do seu ente adoecido. Contudo, eles também sofrem as consequências da dependência química, correspondendo ao afeto existente na relação família e usuário. Portanto, é necessário que este público receba um acompanhamento terapêutico, para que possa haver uma melhor 
interação e compreensão no processo de reabilitação do dependente químico (MACHADO E RODRIGUES, 2017; SOCCOL et al, 2013).

Diante do sofrimento vivido por familiares e dependentes químicos em consequência do uso do crack, os indivíduos voltam-se à espiritualidade/ religiosidade como apoio no enfrentamento da doença, pois busca em Deus, através da fé e da esperança, mudança de vida, favorecendo assim seu bem-estar como regozijo com a vida, felicidade, afeto positivo, melhor saúde física e mental. A família, associada à espiritualidade/religiosidade, pode assumir papel importante na ampla problemática das drogas, através de influências positivas na evolução terapêutica do usuário da substancia psicotrópica, sendo notável a valorização e crescimento da relação espiritual/religiosa com a dependência química, como recurso tratável dentro da área da saúde (ZERBETTO et al, 2017; ZEITOUNE et al, 2012; MEDEIROS et al, 2013).

Dentro do contexto da espiritualidade e religiosidade, ambas são construtos distintos, mas ligados em si, ou seja, a espiritualidade está vinculada a relação pessoal com o transcendente, onde as pessoas buscam o sentido e os propósitos fundamentais a vida. Já a religiosidade trata-se da crença e liturgias de cunho religioso alusivo ao sagrado, podendo ser praticado em comunidade ou individualmente. Nesta perspectiva, a espiritualidade/religiosidade possui grande influência na adequação ao tratamento e reabilitação do dependente químico, pois para eles, as atividades religiosas e espirituais que são desenvolvidas dentro deste processo, trazem conforto, tranquilidade e paz para sua vida (FELIPE et I, 2015; OLIVEIRA et al, 2017).

Neste sentido, pôde-se observar a importância da vivencia, relação familiar e da espiritualidade/religiosidade na evolução terapêutica do dependente usuário de crack, ofertando bem-estar físico e mental. Assim, a revisão literária aqui representada teve como objetivo compreender a vivencia e estratégias de enfrentamento de familiares de dependentes usuários de crack através da análise de intervenções religiosas emergentes para a recuperação.

\section{MÉTODOS}

Com o propósito de atingir o objetivo da pesquisa foi feito um levantamento de artigos publicados nas bases de dados do SciELO (Scientific Eletronic Library Online), REDALYC (Red de Revistas Científicas de América Latina y el Caribe, España y Portugal), Periódicos CAPES (Portal de Periódicos, da Coordenação de Aperfeiçoamento de Pessoal de Nível Superior), Periódicos da Kroton, BVS (Biblioteca Virtual em Saúde) e Google acadêmico, via acesso à Internet, compreendendo o período de 2012 a 2018. Os descritores utilizados para localização dos artigos foram: Relações familiares; Dependência química; Espiritualidade; Religiosidade.

A partir do levantamento dos artigos, executou-se a leitura dos resumos das publicações e foram apartados dezoito artigos condizentes ao propósito da pesquisa, em concordância com os critérios de inclusão e exclusão da pesquisa, e definição das informações a serem extraídas dos estudos selecionados. Os trabalhos apartados foram lidos na íntegra pelos pesquisadores e categorizados de acordo com os seguintes critérios de inclusão: artigos completos, disponíveis em periódicos indexados nas bases de dados acima citadas, nos idiomas português, inglês ou espanhol, convenientes à temática, estar no ano de publicação pré-selecionados. Como critérios de exclusão: Estudos em que o foco não era pertinente à temática e artigos duplicados nas bases de dados.

Com relação à temática proposta pelo estudo, foram considerados para a amostra estudos que contemplaram a vivencia e estratégias de enfrentamento de familiares de dependentes usuários de crack através da análise de intervenções religiosas emergentes para recuperação. O método utilizado para as pesquisas nas bases de dados através dos seguintes descritores: drogas ilícitas, crack, família e drogas, espiritualidade e religiosidade.

\section{RESULTADOS E DISCUSSÃO}

Foram encontrados 18 (dezoito) artigos nos últimos 6 (seis) anos nas bases de dados: 4 (quatro) na REDALYC, 3 (três) na BVS, 4 (quatro) na SCIELO, 4 (quatro) na Periódicos, 1 (um) no Google acadêmico e 2 (dois) na Periódicos da Kroton. . A partir do levantamento bibliográfico foi observada uma concentração maior de artigos publicados no ano de 2013 e 2014, em um período de seis anos (2012 a 2018), o que possibilita analisar que 0 tema em questão é relativamente atual. Houve uma pausa de publicação no ano de 2016, dando continuidade nos anos posteriores com uma variação entre duas e quatro publicações. A distribuição dos estudos que abordaram as vivências e estratégias em enfrentamento de familiares de dependentes usuários de crack e o processo da espiritualidade/religiosidade na recuperação está demonstrada na Quadro 1. 
Quadro 1. Distribuição dos periódicos analisados no presente estudo, que abordaram as relações familiares com dependentes usuários de crack e o processo da espiritualidade/religiosidade na recuperação.

\begin{tabular}{|c|c|c|c|c|c|}
\hline Autores & Periódicos/Ano & Título do Artigo & Objetivos & Amostras & Conclusão \\
\hline $\begin{array}{l}\text { Zeitoune, } \\
\text { Ferreira, } \\
\text { Silveira, } \\
\text { Domingos e } \\
\text { Maia. }\end{array}$ & $\begin{array}{l}\text { Rev. Enf. Esc } \\
\text { Anna Nery. } 2012 .\end{array}$ & $\begin{array}{l}\text { O conhecimento de } \\
\text { adolescentes sobre } \\
\text { drogas lícitas e } \\
\text { llícitas: uma } \\
\text { contribuição para a } \\
\text { enfermagem } \\
\text { comunitária. }\end{array}$ & $\begin{array}{l}\text { Verificar o conhecimento do adolescente, } \\
\text { morador de uma comunidade do rio de } \\
\text { janeiro, sobre as drogas lícitas e ilícitas e } \\
\text { analisar a relevância do conhecimento } \\
\text { perante as ações preventivas sobre esse } \\
\text { fenômeno. }\end{array}$ & $\begin{array}{l}35 \text { adolescentes } \\
\text { entre } 10 \text { e } 19 \\
\text { anos. }\end{array}$ & $\begin{array}{l}\text { Concluiu-se que é preciso priorizar políticas preventivas } \\
\text { em que o enfermeiro desenvolva atividades educativas } \\
\text { com os adolescentes e familiares no intuito de orientar } \\
\text { os jovens e familiares sobre as questões das drogas } \\
\text { lícitas e ilícitas na perspectiva de eliminar ou reduzir o } \\
\text { consumo destas drogas. }\end{array}$ \\
\hline $\begin{array}{l}\text { Capistrano, } \\
\text { Ferreira, } \\
\text { Silva, } \\
\text { Kalinke e } \\
\text { Maftum. }\end{array}$ & $\begin{array}{l}\text { Rev. Enf. Esc } \\
\text { Anna Nery. } 2013 .\end{array}$ & $\begin{array}{l}\text { Perfil } \\
\text { sociodemográfico e } \\
\text { clínico de } \\
\text { dependentes } \\
\text { químicos em } \\
\text { tratamento: análise } \\
\text { de prontuários. }\end{array}$ & $\begin{array}{l}\text { Caracterizar o perfil sociodemográfico e } \\
\text { clínico de dependentes químicos em } \\
\text { tratamento. }\end{array}$ & $\begin{array}{l}350 \text { prontuários } \\
\text { de pacientes com } \\
\text { media de idade } \\
\text { entre } 35.8 \text { anos. }\end{array}$ & $\begin{array}{l}\text { A dependência química atinge diversas idades, } \\
\text { iniciando precocemente na adolescência, e ocasiona } \\
\text { significativas alterações no âmbito biológico, familiar, } \\
\text { social e ocupacional. }\end{array}$ \\
\hline $\begin{array}{l}\text { Maciel, } \\
\text { Zerbetto, } \\
\text { Filizola, } \\
\text { Dupas, } \\
\text { Ferreira. }\end{array}$ & $\begin{array}{l}\text { Rev de APS. } \\
2013\end{array}$ & $\begin{array}{l}\text { Consequências e } \\
\text { dificuldades da } \\
\text { dependência } \\
\text { química no âmbito } \\
\text { familiar: uma } \\
\text { revisão de literatura }\end{array}$ & $\begin{array}{l}\text { Descrever as consequências da } \\
\text { dependência química no âmbito familiar e } \\
\text { identificar as dificuldades enfrentadas } \\
\text { pela família durante o tratamento do } \\
\text { dependente químico. }\end{array}$ & $\begin{array}{l}20 \text { artigos de } \\
\text { periódicos mais } \\
\text { uma tese. }\end{array}$ & $\begin{array}{l}\text { O profissional de saúde necessita de capacitação para } \\
\text { o acompanhamento familiar e revisão de seus } \\
\text { conceitos para instrumentalizar os familiares. }\end{array}$ \\
\hline $\begin{array}{l}\text { Medeiros, } \\
\text { Maciel, } \\
\text { Sousa, } \\
\text { Souza e } \\
\text { Dias. }\end{array}$ & $\begin{array}{l}\text { Rev. Activa. } \\
\text { Psicologia em } \\
\text { Estudo. } \\
2013\end{array}$ & $\begin{array}{l}\text { Representações } \\
\text { sociais do uso e } \\
\text { abuso de drogas } \\
\text { entre familiares de } \\
\text { usuários. }\end{array}$ & $\begin{array}{l}\text { Estudar as representações sociais sobre } \\
\text { as drogas, que foram elaboradas por } 37 \\
\text { familiares de dependentes químicos } \\
\text { (álcool e crack). }\end{array}$ & 37 familiares & $\begin{array}{l}\text { Segundo essas representações, as drogas acarretam } \\
\text { sobrecarga emocional e estado de tensão, } \\
\text { evidenciados por mudanças comportamentais e } \\
\text { questões de ordem financeira, devido ao agravamento } \\
\text { da dependência e às frequentes hospitalizações }\end{array}$ \\
\hline $\begin{array}{l}\text { Gabatz, } \\
\text { Johann, } \\
\text { Terra, } \\
\text { Padoin, Silva } \\
\text { e Brum. }\end{array}$ & $\begin{array}{l}\text { Rev. Enf. Esc } \\
\text { Anna Nery. } 2013 .\end{array}$ & $\begin{array}{l}\text { Percepção do } \\
\text { usuário sobre a } \\
\text { droga em sua vida. }\end{array}$ & $\begin{array}{l}\text { Conhecer a percepção dos usuários } \\
\text { sobre as drogas. }\end{array}$ & $\begin{array}{l}8 \text { usuários de } \\
\text { álcool e outras } \\
\text { drogas rom } \\
\text { idades entre } 18 \text { e } \\
45 \text { anos. }\end{array}$ & $\begin{array}{l}\text { Concluiu-se que é importante desenvolver essa } \\
\text { temática na formação do enfermeiro para que este } \\
\text { possa prestar um cuidado humanizado e efetivo. }\end{array}$ \\
\hline $\begin{array}{l}\text { Jorge, } \\
\text { Quinderé, } \\
\text { Yasui e } \\
\text { Albuquerque. }\end{array}$ & $\begin{array}{l}\text { Rev. Ciência e } \\
\text { Saúde Coletiva. } \\
2013\end{array}$ & $\begin{array}{l}\text { Ritual de consumo } \\
\text { do crack: aspectos } \\
\text { socioantropológicos } \\
\text { e repercussões } \\
\text { para a saúde dos } \\
\text { usuários. }\end{array}$ & $\begin{array}{l}\text { Discutir o ritual de consumo do crack e } \\
\text { suas repercussões sociais e à saúde dos } \\
\text { usuários. }\end{array}$ & $\begin{array}{l}21 \text { usuários de } \\
\text { crack em } \\
\text { acompanhamento } \\
\text { nos } \\
\text { CAPSad; Grupo II } \\
\text { - } 15 \text { trabalhadores } \\
\text { dos CAPSad. }\end{array}$ & $\begin{array}{l}\text { Os indivíduos buscam no crack fazer parte de um } \\
\text { mercado consumidor, participando ativamente do que a } \\
\text { sociedade concebe como novidade. As Formas e as } \\
\text { cenas de uso têm relação direta com a saúde dos } \\
\text { usuários, necessitando que haja por parte dos serviços } \\
\text { de saúde detecção, aproximação e intervenções de } \\
\text { saúde nessas cenas de uso. }\end{array}$ \\
\hline
\end{tabular}

REAS/EJCH | Vol.Sup.19 | e194 | DOI: https://doi.org/10.25248/reas.e194.2019 Página 4 de 8 


\begin{tabular}{|c|c|c|c|c|c|}
\hline $\begin{array}{l}\text { Silva e } \\
\text { Azevedo. }\end{array}$ & $\begin{array}{l}\text { Rev. de } \\
\text { Psicologia. } \\
2013\end{array}$ & $\begin{array}{ll}\text { A importância } & \text { da } \\
\text { família } & \text { no } \\
\text { tratamento } & \text { do } \\
\text { dependente } & \\
\text { químico. } & \end{array}$ & $\begin{array}{l}\text { Analisar a importância que o familiar } \\
\text { exerce no tratamento do usuário, sob o } \\
\text { olhar do próprio dependente e do familiar. }\end{array}$ & $\begin{array}{lr}25 \text { familiares e } 53 \\
\text { usuários } & \text { que } \\
\text { frequentam } & 0 \\
\text { CAPSad. } & \end{array}$ & $\begin{array}{l}\text { Os familiares são de suma importância no tratamento } \\
\text { da dependência química, o qual deve incluir desde a } \\
\text { família nuclear até a família extensa. }\end{array}$ \\
\hline $\begin{array}{l}\text { Paz e } \\
\text { Colossi }\end{array}$ & $\begin{array}{l}\text { Rev. Estudos de } \\
\text { Psicologia. } \\
2013\end{array}$ & $\begin{array}{l}\text { Aspectos da } \\
\text { dinâmica da família } \\
\text { com dependência } \\
\text { química. }\end{array}$ & $\begin{array}{l}\text { O envolvimento da família no tratamento } \\
\text { tem sido apontado como preditor de } \\
\text { sucesso terapêutico da dependência } \\
\text { química. }\end{array}$ & $\begin{array}{l}\text { Estudo de caso } \\
\text { de } 1 \text { paciente. }\end{array}$ & $\begin{array}{l}\text { Tratar a disfuncionalidade familiar pode constituir-se } \\
\text { um fator de proteção ao uso de drogas e prevenção à } \\
\text { recaída. }\end{array}$ \\
\hline $\begin{array}{l}\text { Paula, Jorge, } \\
\text { Albuquerque } \\
\text { e Queiroz. }\end{array}$ & $\begin{array}{l}\text { Rev. Saúde e } \\
\text { Sociedade, USP. } \\
2014\end{array}$ & $\begin{array}{l}\text { Usuário de crack } \\
\text { em situações de } \\
\text { tratamento: } \\
\text { experiências, } \\
\text { significados } \\
\text { sentidos. }\end{array}$ & $\begin{array}{l}\text { Analisar os significados, sentidos e } \\
\text { experiências dos familiares relacionados } \\
\text { ao usuário de crack em situação de } \\
\text { tratamento. }\end{array}$ & $\begin{array}{lr}14 & \text { trabalhadores } \\
\text { de saúde } & \text { que } \\
\text { atuam } & \text { no } \\
\text { CAPSad, } & 21 \\
\text { usuários } & \text { em } \\
\text { tratamento no } \\
\text { CAPSad devido } \\
\text { ao uso de crack, e } \\
4 \text { familiares. }\end{array}$ & $\begin{array}{l}\text { Conclui-se pela importância de se trabalhar os sentidos } \\
\text { e significados dos familiares atribuídos aos usuários de } \\
\text { crack em tratamentos relacionados ao uso da droga. }\end{array}$ \\
\hline $\begin{array}{l}\text { Xavier, } \\
\text { Rodrigues e } \\
\text { Silva. }\end{array}$ & $\begin{array}{l}\text { Rev. de } \\
\text { Psicologia. } \\
2014\end{array}$ & $\begin{array}{lr}\text { A percepção } & \text { da } \\
\text { família } & \text { no } \\
\text { tratamento } & \mathrm{e} \\
\text { suporte } & \text { de } \\
\text { dependentes } & \\
\text { químicos. } & \end{array}$ & $\begin{array}{l}\text { Verificar a percepção dos membros da } \\
\text { família em relação ás formas de } \\
\text { tratamento e de suporte na recuperação } \\
\text { do dependente químico. }\end{array}$ & $\begin{array}{l}12 \text { participantes, } \\
\text { sendo } 4 \text { mães, } 2 \\
\text { pais, } 2 \text { esposas, } 1 \\
\text { irmão, } 1 \text { irmã e } 1 \\
\text { sobrinha de } \\
\text { dependentes } \\
\text { químicos. }\end{array}$ & $\begin{array}{l}\text { Foi possível identificar fatores que são relevantes na } \\
\text { recuperação do dependente químico e o suporte } \\
\text { familiar foi identificado como primordial em todas as } \\
\text { fases do processo de superação da dependência. }\end{array}$ \\
\hline $\begin{array}{l}\text { Silva, } \\
\text { Guimarães e } \\
\text { Salles. }\end{array}$ & $\begin{array}{l}\text { Rev.RENE. } \\
2014\end{array}$ & $\begin{array}{l}\text { Fatores de risco e } \\
\text { proteção à recaída } \\
\text { na percepção de } \\
\text { usuários } \\
\text { substâncias } \\
\text { psicoativas. }\end{array}$ & $\begin{array}{l}\text { Identificar na percepção dos usuários de } \\
\text { substâncias psicoativas, fatores de risco e } \\
\text { proteção à recaída. }\end{array}$ & $\begin{array}{l}50 \text { usuários de } \\
\text { substâncias } \\
\text { psicoativas. }\end{array}$ & $\begin{array}{l}\text { Espera-se que fatores de risco e proteção identificados } \\
\text { contribuam para políticas de prevenção à recaídas, } \\
\text { possibilitando o aprimoramento de tratamentos } \\
\text { voltados ao reconhecimento de fatores de proteção, } \\
\text { desenvolvimento de habilidades e estratégias de } \\
\text { enfrentamento. }\end{array}$ \\
\hline $\begin{array}{l}\text { Gonçalves, } \\
\text { Santos e } \\
\text { Pillon }\end{array}$ & $\begin{array}{l}\text { Rev. Eletrônica } \\
\text { Saúde Mental, } \\
\text { Álcool e Drogas. } \\
2014\end{array}$ & $\begin{array}{l}\text { Uso de álcool e/ou } \\
\text { drogas: avaliação } \\
\text { dos aspectos da } \\
\text { espiritualidade e } \\
\text { religiosos. }\end{array}$ & $\begin{array}{l}\text { Avaliar aspectos da espiritualidade e } \\
\text { religiosos em usuários de álcool e/ou } \\
\text { drogas. }\end{array}$ & $\begin{array}{l}138 \text { usuários de } \\
\text { substâncias } \\
\text { psicoativas. }\end{array}$ & $\begin{array}{l}\text { Os achados ampliam a compreensão sobre como o } \\
\text { enfermeiro pode implementar o cuidado que leva em } \\
\text { consideração os aspectos subjetivos do usuário de } \\
\text { substâncias psicoativas em sua prática cotidiana. }\end{array}$ \\
\hline $\begin{array}{l}\text { Silva, } \\
\text { Weber, } \\
\text { Adan e } \\
\text { Hidalgo. }\end{array}$ & $\begin{array}{l}\text { Rev. Bras. De } \\
\text { Ciências da } \\
\text { Saúde. } \\
2015\end{array}$ & $\begin{array}{l}\text { O papel do trabalho } \\
\text { no processo saúde- } \\
\text { doença } \quad \text { em } \\
\text { dependentes de } \\
\text { crack. }\end{array}$ & $\begin{array}{l}\text { O estudo se propoz a aprofundar o tema } \\
\text { do trabalho e suas repercussões na vida } \\
\text { dos pacientes adultos dependentes de } \\
\text { crack, internados na unidade de } \\
\text { adição/unidade Álvaro Alvim do hospital } \\
\text { de clínicas de porto alegre. }\end{array}$ & $\begin{array}{l}35 \text { pacientes com } \\
\text { idade entre } 18 \text { e } \\
55 \text { anos. }\end{array}$ & $\begin{array}{l}\text { A dependência de crack torna-se um fator dificultador } \\
\text { na vida do trabalhador, ao passo que a estrutura da } \\
\text { sociedade atual parece não tolerar/admitir as } \\
\text { consequências da doença. O trabalho pode ser um fator } \\
\text { protetor quando combinado com outras ações faci- } \\
\text { litadoras do processo de tratamento desses indivíduos. }\end{array}$ \\
\hline
\end{tabular}

REAS/EJCH | Vol.Sup.19 | e194 | DOI: https://doi.org/10.25248/reas.e194.2019 Página 5 de 8 


\begin{tabular}{|c|c|c|c|c|c|}
\hline $\begin{array}{l}\text { Felipe, } \\
\text { Carvalho e } \\
\text { Andrade. }\end{array}$ & $\begin{array}{l}\text { Rev. Eletrônica } \\
\text { Saúde Mental, } \\
\text { Álcool e Drogas. } \\
2015\end{array}$ & $\begin{array}{l}\text { Espiritualidade e } \\
\text { religião como } \\
\text { protetores ao uso } \\
\text { de drogas em } \\
\text { adolescente. }\end{array}$ & $\begin{array}{l}\text { Identificar as evidências disponíveis na } \\
\text { literatura sobre a importância da } \\
\text { religião/espiritualidade como protetores } \\
\text { ao uso de drogas. }\end{array}$ & $\begin{array}{l}\text { Analise de } 12 \\
\text { artigos }\end{array}$ & $\begin{array}{l}\text { Trazer à luz o efeito positivo da religiosidade e da } \\
\text { espiritualidade poderá contribuir para que os } \\
\text { profissionais envolvidos com os adolescentes lancem } \\
\text { intervenções com vistas a reduzir o consumo de drogas } \\
\text { nesse grupo. }\end{array}$ \\
\hline $\begin{array}{l}\text { Soto, } \\
\text { Rozisca e } \\
\text { Cunha. }\end{array}$ & $\begin{array}{l}\text { Rev. Estudos } \\
\text { Interdisciplinares } \\
\text { em Psicologia. } \\
2017\end{array}$ & $\begin{array}{l}\text { Práticas parentais: } \\
\text { reflexões sobre } \\
\text { relatos de familiares } \\
\text { de usuários de } \\
\text { crack. }\end{array}$ & $\begin{array}{l}\text { Compreender práticas parentais em } \\
\text { famílias de usuários de crack. }\end{array}$ & $\begin{array}{l}\text { Pesquisa com } 20 \\
\text { familiares de } \\
\text { usuários de crack. }\end{array}$ & $\begin{array}{l}\text { Conclui-se que tal dinâmica dificulta o desenvolvimento } \\
\text { da regulação emocional, tolerância à contrariedade, } \\
\text { resistência à frustração e habilidades de negociação e } \\
\text { solução de problemas, que podem influenciar no } \\
\text { consumo do crack. }\end{array}$ \\
\hline $\begin{array}{l}\text { Machado e } \\
\text { Rodrigues }\end{array}$ & $\begin{array}{l}\text { Rev.Disciplinarum } \\
\text { Scienti. } \\
2017\end{array}$ & $\begin{array}{lr}\text { Grupos } & \text { de } \\
\text { familiares em CAPS } \\
\text { II: } \quad \text { gerando } \\
\text { reflexões acerca da } \\
\text { participação da } \\
\text { família } \\
\text { tratamento no } \\
\text { usuários. }\end{array}$ & $\begin{array}{l}\text { Relatar a vivência de uma estagiária de } \\
\text { psicologia diante da implantação de um } \\
\text { grupo de familiares de usuários de um } \\
\text { centro de atenção psicossocial (CAPS II) } \\
\text { de uma cidade do Rio Grande Do sul. }\end{array}$ & $\begin{array}{l}\text { Estagio realizado } \\
\text { no período de } 12 \\
\text { meses. }\end{array}$ & $\begin{array}{l}\text { Dessa maneira, entendeu-se que a família é uma } \\
\text { parceira importante no. } \\
\text { Processo de tratamento e reabilitação psicossocial do } \\
\text { usuário da saúde mental. A atenção psicossocial, } \\
\text { associada ao universo familiar, vai facilitar a reinserção } \\
\text { social do sujeito e a promoção da saúde da família } \\
\text { como um todo, considerando todas as dimensões } \\
\text { vividas no cotidiano. }\end{array}$ \\
\hline $\begin{array}{l}\text { Oliveira, } \\
\text { Feitosa, } \\
\text { Santos, } \\
\text { Lima, } \\
\text { Fernandes e } \\
\text { Monteiro. }\end{array}$ & $\begin{array}{l}\text { Rev Rene. } \\
2017\end{array}$ & $\begin{array}{l}\text { Espiritualidade e } \\
\text { religiosidade no } \\
\text { contexto do uso } \\
\text { abusivo de drogas }\end{array}$ & $\begin{array}{l}\text { Investigar a influência da } \\
\text { espiritualidade/religiosidade no contexto } \\
\text { do uso abusivo de drogas. }\end{array}$ & $\begin{array}{l}\text { Analise de } 8 \\
\text { artigos no período } \\
\text { de } 2011 \text { e } 2016\end{array}$ & $\begin{array}{l}\text { A espiritualidade/religiosidade parece favorecer uma } \\
\text { ótica positiva frente ao enfrentamento do tratamento de } \\
\text { usuários, bem como na proteção ao uso abusivo } \\
\text { dessas substâncias psicoativas. }\end{array}$ \\
\hline $\begin{array}{l}\text { Zerbetto SR, } \\
\text { Gonçalves } \\
\text { AMS, Santile } \\
\text { N, Galera } \\
\text { SAF, } \\
\text { Acorinte AC, } \\
\text { Giovannetti } \\
\text { G }\end{array}$ & $\begin{array}{l}\text { Rev. Enf. Esc } \\
\text { Anna Nery. } 2017 .\end{array}$ & $\begin{array}{l}\text { Religiosidade e } \\
\text { espiritualidade: } \\
\text { mecanismos de } \\
\text { influência positiva } \\
\text { sobre a vida e } \\
\text { tratamento do } \\
\text { alcoolista. }\end{array}$ & $\begin{array}{l}\text { Identificar mecanismos de influência } \\
\text { positiva da religiosidade e espiritualidade } \\
\text { na vida e tratamento, na perspectiva de } \\
\text { alcoolistas. }\end{array}$ & $\begin{array}{l}8 \text { usuários de } \\
\text { ambos os sexos e } \\
\text { maiores de } 18 \\
\text { anos. }\end{array}$ & $\begin{array}{l}\text { Os alcoolistas reconhecem a influência positiva da } \\
\text { religiosidade e espiritualidade, ajudando-os no } \\
\text { processo de enfrentamento dos desafios diários da vida } \\
\text { e do tratamento. Profissionais de saúde precisam estar } \\
\text { aptos a utilizar tais temas no cotidiano do cuidado como } \\
\text { recursos motivacionais. }\end{array}$ \\
\hline $\begin{array}{l}\text { Arrieira, } \\
\text { Thofehrn, } \\
\text { Porto, } \\
\text { Moura, } \\
\text { Martins e } \\
\text { Jacondino. }\end{array}$ & $\begin{array}{l}\text { Rev. da Escola. } \\
\text { de Enfermagem } \\
\text { da USP. } \\
2018\end{array}$ & $\begin{array}{l}\text { Espiritualidade nos } \\
\text { cuidados paliativos: } \\
\text { experiência vivida } \\
\text { de uma equipe } \\
\text { interdisciplinar. }\end{array}$ & $\begin{array}{l}\text { Entender a experiência da espiritualidade } \\
\text { no cotidiano de um paliativo. Equipe } \\
\text { interdisciplinar de atendimento. }\end{array}$ & $\begin{array}{l}\text { Entrevista com } \\
\text { profissionais de } \\
\text { saúde no período } \\
\text { de } 4 \text { meses. }\end{array}$ & $\begin{array}{l}\text { Espiritualidade por parte dos profissionais com } \\
\text { pacientes deram significado ao seu trabalho de } \\
\text { cuidados paliativos e facilitaram a formação de vínculos } \\
\text { entre equipes, pacientes e familiares. }\end{array}$ \\
\hline
\end{tabular}

Fonte: Revisão integrativa.

REAS/EJCH | Vol.Sup.19 | e194 | DOI: https://doi.org/10.25248/reas.e194.2019 Página 6 de 8 
Os estudos apontaram uma significativa evolução da dependência química, especificamente o crack, pois se tornou um grave problema de saúde pública associado a fatores biopsicossociais. A dependência de substâncias psicotrópicas é compreendida como uma doença crônica, podendo ser controlada e tratada. $O$ consumo exacerbado da droga traz sérios problemas, tanto para o usuário quanto para a família. Pesquisas realizadas comprovam o grande impacto negativo pelo uso das drogas, pois originam dilemas dentro do convívio social e familiar (PAULA et al, 2014; GABATZ et al, 2013; SOTO et al 2017; ALVAREZ et al, 2014).

$\mathrm{Na}$ classificação das substancias ilícitas, o crack é um tipo de droga que, ao ser consumido de forma ininterrupta, proporciona prejuízos na saúde física, aumentando as possibilidades para a dependência, além de danos sociais. O crack é a forma mais potente da cocaína e seus efeitos atingem, de forma rápida, o cérebro, com efeito curto, levando o usuário a consumir intensamente a substância. Todo esse processo leva a pessoa a se tornar dependente mais rapidamente da droga (PAULA ET AL, 2014; JORGE ET AL, 2013).

Pode-se observar que o trajeto da dependência química torna a família um co-dependente, pois, passa a conviver com esse problema diariamente. O sofrimento da família é paralelo ao do dependente. Algumas famílias reconhecem a dependência química como doença, já em outras, acham que o ente usa a droga porque gosta. Contudo, é necessário que as famílias reconheçam a dependência química como uma doença, pois é de suma importância que a família, ao identificar o problema, busque ajuda para que esta doença seja tratada (GONÇALVES et al, 2014).

Nesse contexto, notadamente, são vários os sentimentos e conflitos vivenciados por familiares e usuários. Em meio ao convívio familiar, há um conflito de sentimentos para ambos, pois expressa medo, angústia, tristeza, sentimento de culpa, alguns chegam ao estremo da depressão que o induzem a pensamentos de suicídio como forma de solucionar o problema (MEDEIROS et al, 2013; SILVA et al, 2014).

Mediante aos conflitos vividos na relação familiar devido ao uso das drogas, o suporte espiritual e religioso tem grande influência no seguimento da reabilitação do dependente químico e dos familiares, pois buscam nas crenças e práticas religiosas forças para o enfrentamento do problema. Desta forma, a religiosidade/espiritualidade são fatores positivos aliados ao processo de recuperação, onde é notável mudanças nos hábitos de vida e melhor interação familiar e social (GONÇALVES et al, 2014; ARRIEIRA et al, 201; de OLIVEIRA et al, 2017).

\section{CONSIDERAÇÕES FINAIS}

A primeira sociedade que o indivíduo faz parte é a família, no entanto é primordial que ela dê apoio ao familiar que é usuário para que ele possa buscar ajuda e tratar esta doença. Dentro desta perspectiva de apoio para a reintegração e recuperação do dependente químico, a religiosidade e a espiritualidade tem fundamental importância neste processo, pois através da sua fé, buscam em Deus, forças para que possam alcançar vitória dentro deste processo de recuperação da dependência química.

Notadamente foi possível identificar, dentro da literatura, que tanto a família quanto o usuário de drogas ilícitas, passam por dificuldades no enfrentamento deste processo de dependência. A religiosidade e espiritualidade possibilitam ao indivíduo um sentido para a vida, pois cria perspectivas de melhora diante do sofrimento enfrentado, relacionado à situação do consumo de drogas. Com isso, quando esses familiares e usuários são inseridos no contexto religioso, começam a dar um novo sentido para a vida, tornando-os mais esperançosos e motivadores de si mesmos.

\section{REFERÊNCIAS}

1. ALVAREZ SQ, GOMES GC, XAVIER DM. Causas da dependência química e suas consequências para o usuário e a família. Rev enferm UFPE on line, 2014; 8(3):641-648.

2. ARRIEIRA ICO, THOFEHRN MB, PORTO, AR et al. Espiritualidade nos cuidados paliativos: experiência vivida de uma equipe interdisciplinar. Rev. da Escola de Enfermagem da USP, 2018; 52:e03312.

3. AZEVEDO CS, SILVA RS. A importância da família no tratamento do dependente químico. 
4. CAPISTRANO FC, FERREIRA ACZ, SILVA TL et al. Perfil sociodemográfico e clínico de dependentes químicos em tratamento: Análise de prontuários. Esc Anna Nery, 2013; 17 (2):234-241.

5. de OLIVEIRA ALCB, FEITOSA CDA, SANTOS AG et al. Espiritualidade e religiosidade no contexto do uso abusivo de drogas. Rev Rene, 2017; 18(2): 283-90.

6. FELIPE AOB, CARVALHO AMP, ANDRADE CUB. Espiritualidade e religião como protetores ao uso de drogas em adolescente. Rev. Eletrônica Saúde Mental Álcool Drog, 2015; 11(1): 49-58.

7. GABATZ RIB, JOHANN M, TERRA MG et al. Percepção do usuário sobre a droga em sua vida. Esc. Anna Nery [online], 2013; 17(3): 520-525.

8. GONÇALVES AMD, SANTOS MA, PILLON SC. Uso de álcool e/ou drogas: Avaliação dos aspectos da espiritualidade e religiosos. Rev. Eletrônica Saúde Mental Álcool Drog, 2014; 10(2): 61-9.

9. JORGE MSB, QUINDERÉ PHD, YASUI S ET AL. Ritual de consumo do crack: aspectos socioantropológicos e repercussões para a saúde dos usuários. Ciência \& Saúde Coletiva, 2013; 18(10): 2909-2918.

10. MACHADO BR, RODRIGUES T. Grupos de famílias em CAPS II: Gerando reflexões acerca da participação da família no tratamento dos usuários. Disciplinarum Scientia. Série: Ciências Humanas, 2017; 18(1):171-180.

11. MACIEL LD, ZERBETTO SR, FILIZOLA CLA et al. Consequências e dificuldades da dependência química no âmbito familiar: uma revisão de literatura. Rev APS, 2013; 16(2): 187-196.

12. MARQUES ACPR, RIBEIRO M, LARANJEIRA RR et al. Abuso e dependência: crack. Rev Assoc Med Bras, 2012; 58(2):141-153.

13. MEDEIROS KT, MACIEL SC, SOUSA PF et al. 2013. Representações sociais do uso e abuso de drogas entre familiares de usuários. Psicologia em Estudo, 2013; 18(2): 269-279.

14. OLIVEIRA ALB, FEITOSA CDA, SANTOS AG et al. Espiritualidade e religiosidade no contexto do uso abusivo de drogas. Rev Rene, 2017; 18(2): 283-90.

15. PAULA ML, JORGE MSB, ALBUQUERQUE RA. 2014. Usuários de crack em situações de tratamento: experiências, significados e sentidos. Saude soc. [online], 2014; 23 (1): 118-130.

16. PAZ FM, COLOSSI PM. Aspectos da dinâmica da família com dependência química. Estudos de Psicologia, 2013; 18(4): $551-558$.

17. SILVA AC, WEBER F, ADAN A. O papel do trabalho no processo saúde-doença em dependentes de crack. Arquivos de Ciências da Saúde, 2015; 22(1): 48-52.

18. SILVA ML, GUIMARÃES CF, SALLES DB. Fatores de risco e proteção à recaída na percepção de usuários de substâncias psicoativas. Revista da Rede de Enfermagem do Nordeste, 2014; 15(6): 1007-1015.

19. SOCCOL KLS, TERRA MG, GIRARDON-PERLINI NMO et al. O cuidado familial ao indivíduo dependente de álcool e outras drogas. Revista Rene, 2013; 14(3): 549-57.

20. SOTO MGR, ROZISCA VF, CUNHA RV. Estudos Interdisciplinares em Psicologia. Práticas parentais: reflexões sobre relatos de familiares de usuários de crack. Estudos Interdisciplinares em Psicologia, 2017; 8(1): 100-118.

21. XAVIER MF, RODRIGUES PHJ, SILVA MCR. A percepção da família no tratamento e suporte de dependentes químicos. Revista de Psicologia, 2014;17(26): 99-110.

22. ZEITOUNE RCG, FERREIRA VS, SILVEIRA HS. O conhecimento de adolescentes sobre drogas lícitas e ilícitas: Uma contribuição para a enfermagem comunitária. Esc. Anna Nery, 2012; 16(1):57-63.

23. ZERBETTO SR, GONÇALVES AMS, SANTILE N. Religiosidade e espiritualidade: mecanismos de influência positiva sobre a vida e tratamento do alcoolista. Esc. Anna Ner, 2017; 21(1): e20170005. 